\title{
Effect of Betong Watercress and Phenethyl Isothiocyanate on N-Demethylation of Caffeine in Rats
}

\author{
Benjamas Janchawee ${ }^{1,2 *}$, Angkana Wongsakul ${ }^{1}$, Sathaporn Prutipanlai ${ }^{1}$ and \\ Pritsana Ruangrut ${ }^{3}$ \\ ${ }^{1}$ Department of Pharmacology, ${ }^{2}$ Natural Product Research Center, Faculty of Science, ${ }^{3}$ Department of Biomedical Sciences, \\ Faculty of Medicine, Prince of Songkla University, Songkhla 90112, Thailand
}

*For correspondence: Email: benjamas.j@psu.ac.th; Tel: +66-74-446678; Fax: +66-74-446678

\begin{abstract}
Purpose: To investigate the effect of Betong watercress and phenethyl isothiocyanate (PEITC) on the $\mathrm{N}$-demethylation of caffeine (CF) in rats

Methods: Male Wistar rats were subjected to 2 phases of experiment. Phase I, they received a single oral dose of CF $(10 \mathrm{mg} / \mathrm{kg})$, while in phase II, they were pretreated with the following regimens: 10 $\mathrm{mg} / \mathrm{kg}$ fluvoxamine, i.p.; a single oral dose of 2, 10, and $20 \mathrm{mg} / \mathrm{kg}$ PEITC; 2, 10, and $20 \mathrm{mg} / \mathrm{kg}$ PEITC, once daily for five days; single oral dose of $800 \mathrm{mg} / \mathrm{kg}$ Betong watercress; $800 \mathrm{mg} / \mathrm{kg}$ Betong watercress once daily for five days, before receiving the same dose of CF as in phase $\mathrm{I}$. Serum concentrations of $\mathrm{CF}$ and its metabolites after $3 \mathrm{~h}$ of $\mathrm{CF}$ administration were measured. Caffeine metabolic ratios (CMRs) and ratio of serum concentration of metabolites to that of CF were calculated and compared.

Results: CMRs were decreased by a single pretreatment lwith fluvoxamine (30-40\%), PEITC (2 - 20 $\mathrm{mg} / \mathrm{kg})(40-55 \%)$, and Betong watercress (9-22\%). The decreases caused by 10 and $20 \mathrm{mg} / \mathrm{kg}$ PEITC were significantly greater than those by fluvoxamine. CMRs were also decreased after five days of pretreatment with all doses of PEITC (43 - 69\%) and Betong watercress (28 - 44\%). The reduction in metabolic ratio after single- and multiple PEITC pretreatments was dose- and time-independent.

Conclusion: Betong watercress and PEITC inhibit N-demethylation of CF in rats. Such an effect indicates that they have inhibitory activity on CYP1A2 and CYP2C.
\end{abstract}

Keywords: Watercress, Phenethyl isothiocyanate, Caffeine, N-demethylation, Fluvoxamine, Cytochrome

Tropical Journal of Pharmaceutical Research is indexed by Science Citation Index (SciSearch), Scopus, International Pharmaceutical Abstract, Chemical Abstracts, Embase, Index Copernicus, EBSCO, African Index Medicus, JournalSeek, Journal Citation Reports/Science Edition, Directory of Open Access Journals (DOAJ), African Journal Online, Bioline International, Open-J-Gate and Pharmacy Abstracts

\section{INTRODUCTION}

Watercress (Nasturtium officinale R.Br.) and other members of the Cruciferae (Brassicaceae) contain glucosinolates which can be hydrolysed by myrosinase to isothiocyanates (ITCs) after chewing. In the crucifer family, watercress contains the largest amounts of ITCs, mostly phenethyl isothiocyanate (PEITC) [1] which is a dietary substance that has a protective effect against chemical carcinogen-induced tumors in animals [2].

Watercress and PEITC influence phases I \& II drug metabolizing enzymes. Watercress inhibits the CYP2E1-mediated metabolism of some drugs [3, 4], but higher doses enhance the activity of ethoxyresorufin-O-deethylase (EROD; CYP1A), and $\mathrm{NAD}(\mathrm{P}) \mathrm{H}$-quinonereductase, in a dose-dependent manner [5]. The effect of the 
PEITC on CYP1A expression and activity is still unclear. An in vitro study has demonstrated that CYP1A2 and other isoforms are inhibited by PEITC [6]. However, an animal study has shown inconsistent effects of PEITC on CYP1A activity [7].

Betong watercress (Phak Num Betong; Fig. 1A) is a variety of watercress cultivated in Thailand, mostly in the South at the Betong District of Yala Province. It is claimed that this plant is originally from France and has been brought to grow in China and then in Thailand by Chinese immigrants. However, its scientific name has never been formally confirmed. Additionally, no evidence of its effects on drug metabolizing enzymes such as CYP1A2 has been reported. Caffeine $(\mathrm{CF})$ is primarily metabolized via $\mathrm{N}$ demethylation to paraxanthine (PX), theobromine (TB) and theophylline (TP) and C-8-hydroxylation to 1,3,7-trimethyluric acid (TMU) in humans and rats. These reactions are mainly mediated by CYP1A2. CF is a marker for determining any influence of xenobiotics on this enzyme activity and caffeine metabolic ratios (CMRs) are acceptable indicators for determining CYP1A activity in humans and rats [8].

The aim of this study was to investigate the effects of BW and PEITC on caffeine $\mathrm{N}$ demethylation in rats.

\section{EXPERIMENTAL}

\section{Chemicals}

Standard CF, TB, TP, PX, PEITC, fluvoxamine (FV), acetaminophen (AP), 1,2-benzenedithiol, and myrosinase were obtained from SigmaAldrich, USA. HPLC grade acetonitrile and tetrahydrofuran were obtained from Mallinckrodt Baker Inc., USA. All other chemicals were of analytical reagent grade.

\section{Animals}

Adult male Wistar rats (195 - 220 g) were obtained from Southern Laboratory Animal Facility, Prince of Songkla University. The animal experiments were approved by the Animal Ethics Committee, Prince of Songkla University (ref. 17/51). The animals were handled in accordance with the guidelines of the National Research Council of Thailand based on the International Guiding Principles for Biomedical Research Involving Animals [9].

\section{Authentication and preparation of Betong watercress}

In December 2009, Betong watercress was purchased from a local farm at Betong district, Yala province, Thailand. The whole plant was identified at the Princess Maha Chakri Sirindhorn Natural History Museum, Prince of Songkla University where the voucher specimen ( $B$. Janchawee 1; Fig. 1B) has been deposited.

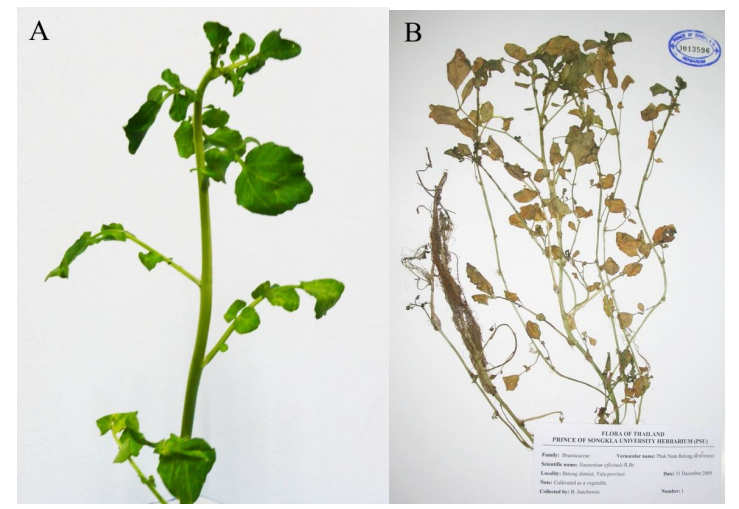

Fig 1: Betong watercress (Phak Num Betong; Nasturtium officinale R.Br.) collected from Betong district, Yala province by B. Janchawee; (A) fresh plant; (B) a voucher specimen (B. Janchawee \#1).

To prepare a dry powder, fresh Betong watercress $(10 \mathrm{~kg})$ was cleansed, roughly chopped and mixed with deionized water before homogenizing with a kitchen blender. The paste was wrapped with cheese cloth and squeezed to release the juice. The residue was mixed with another portion of deionized water and squeezed again. All extracts were pooled then lyophilized.

\section{Experimental design}

An experiment consisted of phase I, referring to a single oral dose administration of CF (10 mg/kg), and phase $\mathrm{II}$, referring to pretreatment with the study drugs before receiving the same dose of CF as in phase I. The wash-out period was two days. Rats were randomly divided into nine groups $(n=6)$ which were assigned different pretreatments as follows. Group I, the animals were intraperitoneally injected with fluvoxamine at a single dose of $10 \mathrm{mg} / \mathrm{kg}$. Groups II, III, and IV, the animals were pretreated with a single dose of PEITC at the doses of 2, 10, and 20 $\mathrm{mg} / \mathrm{kg}$, respectively. Groups V, VI, and VII, the animals were pretreated with multiple doses of PEITC at the doses of 2, 10, and $20 \mathrm{mg} / \mathrm{kg}$, respectively, once daily for five days. The animals in group VIII were administered a single dose of $800 \mathrm{mg} / \mathrm{kg}$ of dry powders of Betong watercress juice while those in group IX received 
the same dose of Betong watercress once daily for 5 days.

PEITC was dissolved in corn oil. The dry powder of Betong watercress was suspended in $20 \%$ aqueous acacia. Blood samples were taken before and $3 \mathrm{~h}$ after CF administration in phase I and phase II. Serum was separated by centrifugation at $1000 \mathrm{xg}$ for $20 \mathrm{~min}$.

\section{Analysis of CF, PX, TB, and TP in serum}

\section{Preparation of standard solutions}

Stock solutions of CF and AP (internal standard) were prepared in deionized water. Those of PX and TP were prepared in $0.1 \mathrm{M}$ ammonium hydroxide. That of TB was prepared in $0.1 \mathrm{M}$ sodium hydroxide. Working solutions (0.08 - 40 $\mu \mathrm{g} / \mathrm{mL}$ ) were prepared as a mixture with deionized water. Calibration standard mixtures $(0.02-10 \mu \mathrm{g} / \mathrm{mL})$ containing AP $(25 \mu \mathrm{g} / \mathrm{mL})$ were prepared.

\section{Sample extraction}

Based on the modified method [10], serum (200 $\mu \mathrm{L})$ was combined with $\mathrm{AP}(100 \mu \mathrm{g} / \mathrm{mL}, 50 \mu \mathrm{L})$ and ammonium sulphate $(60 \mathrm{mg})$. A mixture of chloroform-isopropanol $(85: 15, \mathrm{v} / \mathrm{v}, 6 \mathrm{~mL})$ was added and mixed (30 s). After centrifugation $(875 \times \mathrm{g}, 15 \mathrm{~min})$, the organic phase was evaporated. The residue was reconstituted in the mobile phase $(100 \mu \mathrm{L})$ for HPLC analysis.

\section{Chromatographic method}

The HPLC system consisted of Waters 2695 Separations Module and a Waters 5487 dual $\lambda$ absorbance detector (Milford, MA, USA). Data were processed using the EmpowerTM Software System. Separation was modified based on the previous method [11]. A Symmetry® C18 column $(250 \times 4.6 \mathrm{~mm}$ i.d., $5 \mu \mathrm{m})$ connected to a SymmetryTM guard column $(20 \times 3.9 \mathrm{~mm}$ i.d., 5 $\mu \mathrm{m})$ was used and controlled at $32^{\circ} \mathrm{C}$. A wateracetic acid-tetrahydrofuran mixture (996.5:1:2.5, $\mathrm{v} / \mathrm{v} / \mathrm{v}$ ) was the mobile phase $A$, while acetronitrile was the mobile phase $B$. The gradient elution was as follows; $\mathrm{B}, 6 \%$ at $0-9 \mathrm{~min}$, increased to $15 \%$ from 9 to $10 \mathrm{~min}$ (curve 10), decreased to $6 \%$ from 10 to 11 min (curve 6), and post run equilibration of $3 \mathrm{~min}$. The flow rate was 1.3 $\mathrm{mL} / \mathrm{min}$. The sample $(20 \mu \mathrm{L})$ was detected at $274 \mathrm{~nm}$.

\section{Determination of PEITC in Betong watercress}

\section{Preparation of standard solutions}

A stock solution of PEITC in acetronitrile was diluted to different concentrations $(0.1-30$ $\mu \mathrm{g} / \mathrm{mL}$ ). Calibration standard solutions (0.3 - 5 $\mu \mathrm{g} / \mathrm{mL}$ ) were prepared by adding $100 \mu \mathrm{L}$ of the working standard solutions in cyclocondensation reagents, i.e., $600 \mu \mathrm{L}$ of $10 \mathrm{mM}$ 1,2benzenedithiol in isopropanol and $500 \mu \mathrm{L}$ of $0.1 \mathrm{M}$ phosphate buffer $(\mathrm{pH}$ 8.5). The mixture was incubated as described in the next section.

\section{Sample derivatization}

Determination of PEITC required two steps; 1) hydrolysis of glucosinolates, and 2) ITC derivatization via the cyclocondensation reaction [12]. Samples $(n=3)$ of Betong watercress dry powder $(2 \mathrm{mg}$ ) were dissolved in deionized water $(2 \mathrm{~mL})$, then mixed with myrosinase solution (1 $\mathrm{mL}$ ) and incubated at $37^{\circ} \mathrm{C}$ for $2 \mathrm{~h}$. After centrifugation ( $875 \times \mathrm{g}, 15 \mathrm{~min})$, the supernatant $(100 \mu \mathrm{L})$ was mixed with cyclocondensation reagents, then incubated at $65^{\circ} \mathrm{C}$ for $2 \mathrm{~h}$ prior to HPLC injection.

The amount of PEITC per $1 \mathrm{mg}$ of Betong watercress dry power (Amt. PEITC) was calculated using the equation (1).

Amt. $_{\text {PEITC }}(\mu \mathrm{g})=\left(\frac{\mathrm{C}_{\text {Final }} \times \mathrm{V}_{2}}{\mathrm{~V}_{1}}\right) \times \mathrm{V}_{3} / \mathrm{W}$

$\mathrm{C}_{\text {Final }}$ is the final concentration of PEITC measured by HPLC; $V_{1}$ is the volume of the aliquot from the myrosinase reaction $(0.1 \mathrm{~mL}) ; \mathrm{V}_{2}$ is the total volume of the derivatizing reaction mixture $(1.2 \mathrm{~mL}) ; V_{3}$ is the total volume of the myrosinase reaction mixture $(3 \mathrm{~mL})$; and $\mathrm{W}$ is the weight of dry powder used in the reaction.

\section{Chromatographic method}

Separation was modified from the previous method [12]. The Fortis $₫$ C18 column (150×4.6 $\mathrm{mm}$ i.d., $5 \mu \mathrm{m}$ ) connected to a guard column, Sunfire $\AA(20 \times 4.6 \mathrm{~mm}$ i.d., $5 \mu \mathrm{m})$ was used and controlled at $25^{\circ} \mathrm{C}$. The mobile phase was a methanol-water mixture $(90: 10, \mathrm{v} / \mathrm{v})$ flowed at 1.1 $\mathrm{mL} / \mathrm{min}$. The sample $(20 \mu \mathrm{L})$ was detected at 365 $\mathrm{nm}$.

\section{Method validation}

The analytical methods were validated in accordance with the USFDA guidance [13] in terms of linearity, precision, accuracy, recovery of extraction (except for PEITC), and lower limit of quantification (LLOQ). For CF and it metabolites, spiked serum samples (0.02-10 $\mu \mathrm{g} / \mathrm{mL}, \quad \mathrm{n}=5$ ) were used. The LLOQ was determined with a precision of $20 \%$ and accuracy of $80-120 \%$. For PEITC, standard samples $(0.1-$ $30 \mu \mathrm{g} / \mathrm{mL}, \mathrm{n}=5)$ in the cyclocondensation reagents were used. The peak area of its derivative (1,3-benzenedithiole-2-thione) was 
measured. The LLOQ was determined based on signal to noise ratio $(S / N) \geq 5$.

Validation showed that calibration curves for $\mathrm{CF}$ and its metabolites were linear $(r>0.9990)$. All analytes were completely extracted from the serum. Ranges of intra- and inter-day precision for CF, PX, TP, and TB were 2.8-13.4, 2.3-9.3, 2.1-7.3, and 3.5-6.5\% RSD, respectively. Ranges of intra- and inter-day accuracy were $-11.5-(+)$ 18.5, - -5.7-(+) 11.3, -18.2-(+) 8.3, and $-4.6-(+)$ $17.9 \%$ DEV, respectively. The LLOQs of CF and PX was $0.02 \mu \mathrm{g} / \mathrm{mL}$, while those for TP and TB were 0.04 and $0.08 \mu \mathrm{g} / \mathrm{mL}$, respectively.

Calibration curve of the peak area of the derivative plotted against PEITC concentrations also showed good linearity $(r=0.9999)$. The intra- and inter-day precision range was $0.6-4.1 \%$ RSD. The intra- and inter-day accuracy range was $-7.5-(+) 18.2 \%$ DEV. The LLOQ was 0.1 $\mu \mathrm{g} / \mathrm{mL}$.

\section{Data analysis}

All data were expressed as mean \pm SE. CMRs were calculated as the ratios of the serum concentration of each metabolite to that of $\mathrm{CF}$ (TB/CF, PX/CF, and TP/CF), and total serum concentrations of metabolites to that of $\mathrm{CF}$ $(\mathrm{TB}+\mathrm{PX}+\mathrm{TP} / \mathrm{CF})$. CMRs in phases I and II experiments were compared using Student's paired t-test. The percentage changes in MRs among different groups of drug pretreatment for each MR parameter was analyzed by using ANOVA followed by LSD test, while those for single- and multiple pretreatments were
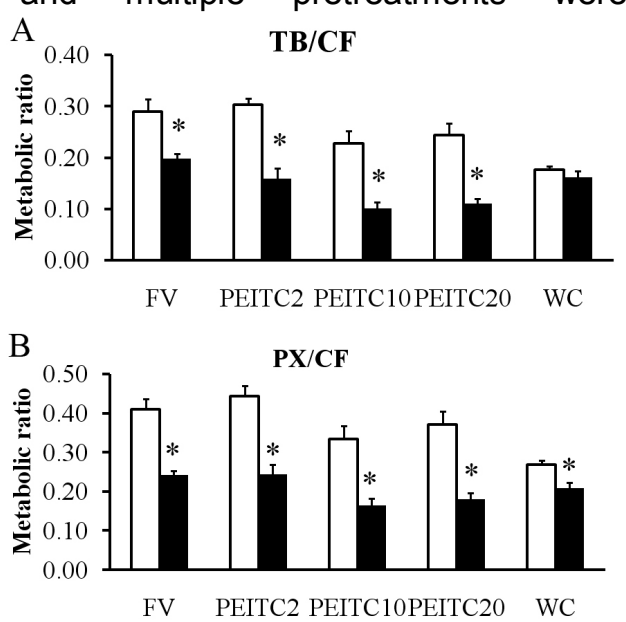

compared by Student's t-test. A statistically significant difference was accepted at $p<0.05$.

\section{RESULTS}

\section{Chromatographic profiles}

$\mathrm{CF}, \mathrm{TB}, \mathrm{PX}$, and TP either in the spiked serum (Fig. 2A) or in real serum samples (Fig. 2B), were well separated within $13 \mathrm{~min}$. The derivative product of PEITC was eluted at 3.91 min and it was also well separated with no interference (data not shown).
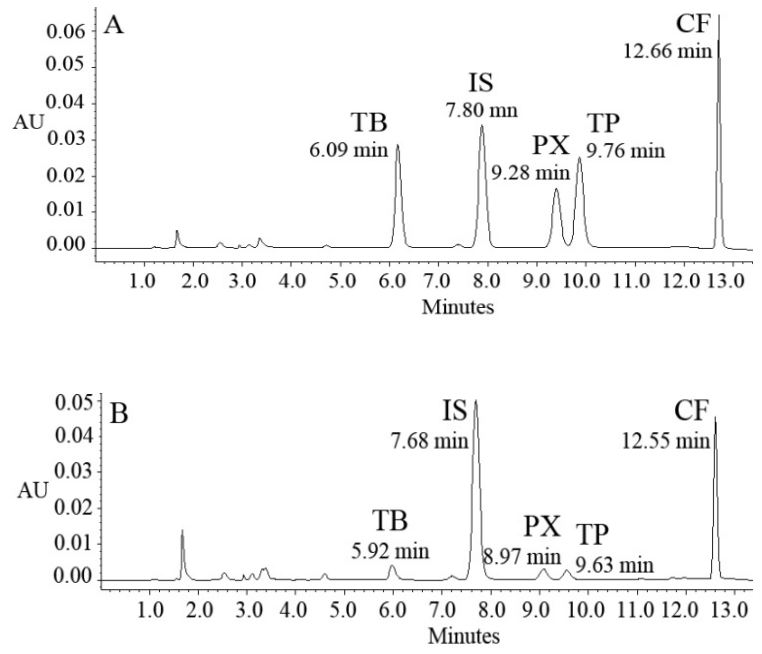

Fig 2: Chromatograms of CF and its metabolites; (A) rat serum spiked with internal standard (IS; $25 \mu \mathrm{g} / \mathrm{mL}$ ) and standard TB, PX, TP, and CF $(4.5 \mu \mathrm{g} / \mathrm{mL}) ;(B)$ serum sample at $3 \mathrm{~h}$ after $\mathrm{CF}$ administration.
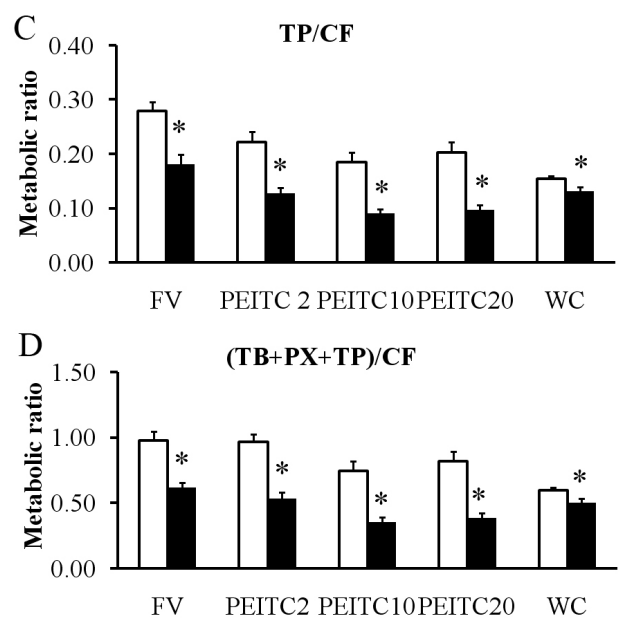

Fig 3: $\quad$ CMRs (A-D) in rats $(n=6)$ receiving CF alone (phase I; $\square$ ) and pretreated with FV, PEITC, and Betong watercress (WC) prior to receiving the same dose of caffeine (phase II; $\square$ ); ${ }^{*} p<0.02$ compared with phase I 
A
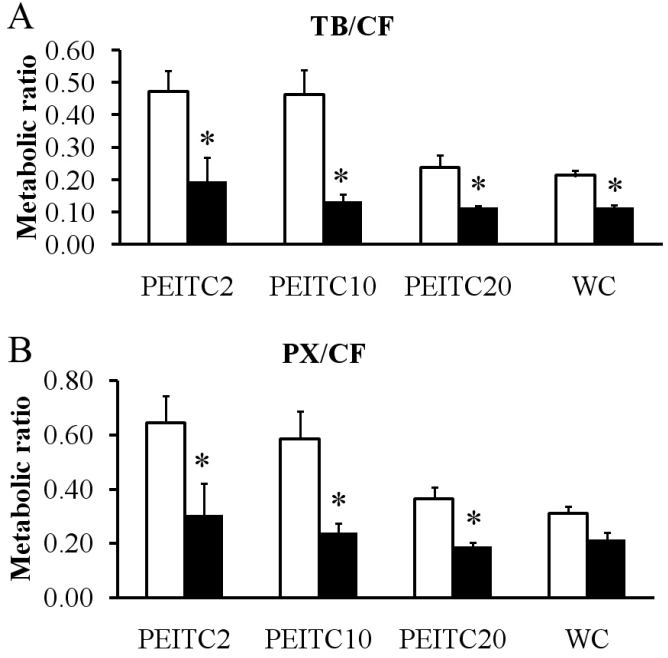
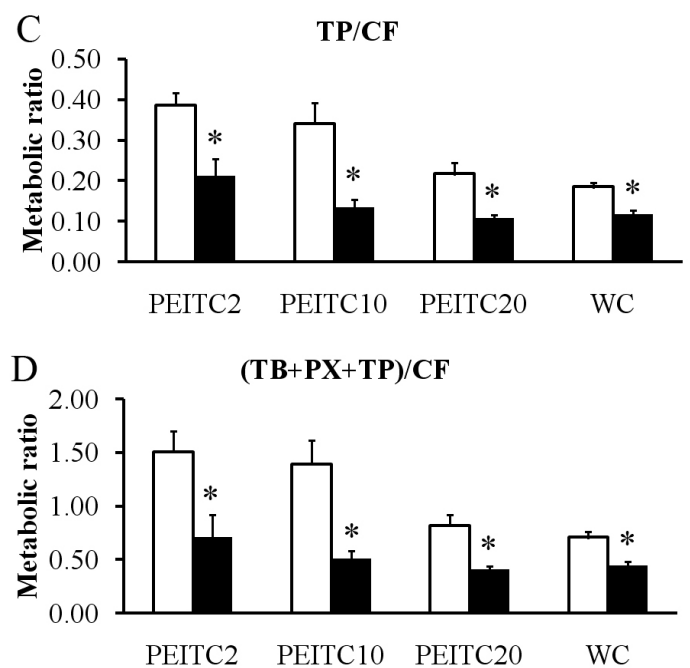

Fig 4: CMRs $(A-D)$ in rats $(n=6)$ receiving CF alone (phase l; $\square$ ) and five-day pretreatment with PEITC, and WC prior to receiving the same dose of $\mathrm{CF}$ (phase II; $\square$ ); ${ }^{*} p<0.03$ compared with phase I



Fig 5: Reduction in CMRs $(\%)$ in rats $(n=6)$ receiving a single- and multiple pretreatments with FV, PEITC, and WC; ${ }^{a}$ compared with FV; ${ }^{b}$ compared with PEITC 2, PEITC 10, and PEITC 20; ${ }^{\circ}$ compared with PEITC 2; compared with PEITC $10 ;{ }^{\mathrm{e}}$ compared with a single dose

\section{Caffeine metabolic ratios}

The effect of a single pretreatment of FV, PEITC, and Betong watercress on the CMRs are shown in Fig. 3. FV (10 mg/kg, i.p.) caused a significant reduction of CMRs (TB/CF, PX/CF, TP/CF, and $T B+P X+T P / C F)$ in phase II compared with phase I. Similar results were obtained with different doses of PEITC (2, 10, and $20 \mathrm{mg} / \mathrm{kg}$, p.o.). Pretreatment with Betong watercress (800 $\mathrm{mg} / \mathrm{kg}$, p.o.) also resulted in a significant decrease in PX/CF, TP/CF, and TB+PX+TP/CF ratios, but not $\mathrm{TB} / \mathrm{CF}$ ratio.

The effect of a five-day pretreatment with similar doses of pure PEITC and PEITC in Betong watercress on CMRs are shown in Fig 4. All doses of PEITC caused a significant reduction in phase II CMRs (TB/CF, PX/CF, TP/CF, and $\mathrm{TB}+\mathrm{PX}+\mathrm{TP} / \mathrm{CF}$ ). Multiple pretreatment with Betong watercress also significantly decreased phase II CMRs (TB/CF, TP/CF, and $\mathrm{TB}+\mathrm{PX}+\mathrm{TP} / \mathrm{CF}$, but not $\mathrm{PX} / \mathrm{CF}$ ).

The reductions in CMRs are presented in Fig. 5. After a single pretreatment, FV decreased CMRs by $30-40 \%$. PEITC $(2-20 \mathrm{mg} / \mathrm{kg})$ decreased CMRs by $40-55 \%$ in a dose-independent pattern. The decreases of TB/CF and TB+PX+TP/CF ratios caused by $10-20 \mathrm{mg} / \mathrm{kg}$ PEITC, i.e., $50-$ $55 \%$, were significantly greater than those caused by FV. The decreases in CMRs caused 
by Betong watercress were $9-22 \%$ and these were significantly less than those caused by FV and PEITC at all doses. Multiple doses of PEITC caused 43-69\% MR reduction which was not significantly different when compared with a single dose pretreatment. In a similar way to a single dose, no dose-dependency of PEITC was seen. Multiple pretreatments with Betong watercress caused $28-44 \%$ reduction in the TB/CF and TP/CF ratios which were significantly greater than those obtained from a single pretreatment.

\section{DISCUSSION}

In humans and rats, CF is primarily metabolized via $\mathrm{N}$-demethylation to TB (1-N position), PX (3$\mathrm{N}$ position), and TP (7-N position), and via C-8hydroxylation to TMU. The recent in vitro experiments using cDNA-expressed P450s, liver microsomes and specific P450 inhibitors have demonstrated the different relative contributions of CYP isoforms to the metabolism of caffeine in both species. In humans, 3-N-demethylation is the main pathway $(\sim 70 \%)$ compared to $1-\mathrm{N}-$ and 7-N-demethylation (7-8\%) and C-8-hydroxylation ( 15\%). Both $3-\mathrm{N}-$ and $1-\mathrm{N}-$ demethylation are specifically catalyzed by CYP1A2. 7-NDemethylation is catalyzed mainly by CYP1A2 and with a lesser extent by CYP2C8/9 and CYP3A4. In contrast, C-8-hydroxylation is the major route $(-70 \%)$ in rats compared to $1-\mathrm{N}-$ and 7-N-demethylation (8-9\%) and 3-N-demethylation ( 13\%). C-8-Hydroxylation is mainly regulated by CYP1A2 (72\%). 1-N- and 3-N-Demethylation are contributed by CYP1A2 with the proportion of $37.5 \%$ and $47 \%$, respectively. 3-N-Demethylation is also regulated by CYP2C11 (31\%). 7-NDemethylation is regulated mostly by CYP2C subfamily $(\sim 66 \%)$ particularly CYP2C6 and CYP2C11 [8].

The present study determined CMRs that can reflect an alteration in CF metabolism rate and the relevant CYP isoform activities. Although the hydroxylation is the major route in rats, only MRs representing the demethylation was investigated in this study due to the lack of the commercial standard of the metabolite TMU. However a change in demethylation MRs indicates the modification of activity of CYP1A2 and CYP2C that contribute to such reactions in this species.

The decreases of TB/CF, PX/CF, TP/CF ratios after single- and multiple pretreatments of PEITC and Betong watercress were most likely caused by inhibition of CYP1A2 and/or CYP2C. This is consistent with the in vitro study that used microsomes from baculovirus-infected insect cells expressing human CYP isoforms, and demonstrated that PEITC competitively inhibited CYP1A2 and noncompetitively inhibited CYP2C9, CYP2C19 but not CYP2C8 [6]. Another work [7] studying the enzyme activity in rats receiving PEITC for 2 weeks showed that only the low dose $(1.1 \mathrm{mg} / \mathrm{kg})$ of PEITC decreased CYP1A1 and CYP1A2 activity, and the higher doses (11 and $110 \mathrm{mg} / \mathrm{kg}$ ) increased CYP3A activity. No data have yet indicated an influence of PEITC on CYP2C6 or CYP2C11.

The present study showed that a 5-day pretreatment with PEITC exhibited a similar inhibition of CF demethylation to a single pretreatment, i.e., $43-69 \%$ vs. $40-55 \%$, respectively. This indicates a time-independent manner of CYP1A2 and CYP2Cs inhibition of PEITC. The inhibitory effect of PEITC (2-20 $\mathrm{mg} / \mathrm{kg}$ ) showed dose-independent pattern both for single- and multiple dose-pretreatments. The percentage decrease of CMRs after a single high dose of PEITC tended to increase although no statistical significance was noted. After multiple high doses, the percentage decrease of CMRs appeared to decrease. Such dose-independent inhibition may be due to the non-linear pharmacokinetic behavior of PEITC as demonstrated in the earlier study [14]. The authors investigated the kinetics of a single dose administration of PEITC in rats and described that clearance tended to decrease and the volume of distribution tended to increase after higher doses, i.e., > $10 \mu \mathrm{mol} / \mathrm{kg}(1.65 \mathrm{mg} / \mathrm{kg})$.

This work used FV as a reference inhibitor although its potent CYP1A2 inhibitory effect has been mostly established in human studies. FV also has inhibitory effects on CYP2C19 in humans [15]. This study shows that FV at the dose of $10 \mathrm{mg} / \mathrm{kg}$, which was lower than that known to exert its pharmacological action in rats, i.e., $25 \mathrm{mg} / \mathrm{kg}$ [16] inhibited both CYP1A2 and CYP2Cs as noted by the $30-40 \%$ decrease in CMRs.

To investigate the effect of Betong watercress on CF demethylation, the preparation derived from fresh, not cooked, vegetable was used. It has been recognized that ITCs are products of glucosinolate-myrosinase hydrolysis. Myrosinase located separately from glucosinoates in plant cells [17]. When humans ingest fresh watercress, plant cells are damaged by chewing, and the enzyme is released and rapidly catalyzes conversion of gluconasturtiin to PEITC. By using urinary $\mathrm{N}$-acetylcysteine conjugate as a marker, 
consumption of $57 \mathrm{~g}$ of fresh watercress resulted in a $30-67 \%$ conversion of gluconasturtiin corresponding to $12-15 \mathrm{mg}$ (72.6 - $90.7 \mu \mathrm{mole})$ of PEITC in the body [18]. For cooked watercress, cooking diminishes the concentration of glucosinolates in plant tissue and also inactivates myrosinase [19]. In individuals ingested cooked watercress in which myrosinase is completely inactivated by cooking, glucosinolates are converted to ITCs via colonic microflora. However, the extent of conversion is substantially less than after ingesting the uncooked vegetable [20].

The present work has ensured that the dry powder of fresh juice preparation contained PEITC. During blending of the fresh plant to prepare juice, glucosinolates come into contact with endogenous myrosinase and hydrolysis was rapidly initiated. It was likely that juice contained PEITC as reported earlier, and that PEITC was a component of watercress juice with a concentration of $24 \mathrm{mg} / \mathrm{L}$ [21]. In addition, it is likely that glucosinolates, which are water soluble, at the cut surfaces of plant cells leached out during blending process. Hence Betong watercress juice probably also contained glucosinolate precursors that will be changed to PEITC in the gut. After incubation of the dry powders of juice with exogenous myrosinase, it was found that the PEITC content was 2.50 $\mu \mathrm{g} / \mathrm{mg}$ dry powders or $15.1 \mu \mathrm{mole} / \mathrm{g}$ dry powders which was equivalent to $68.5 \mathrm{~g}$ of fresh vegetable.

Dry powder of Betong watercress administered at a dose of $800 \mathrm{mg} / \mathrm{kg}$, which is equivalent to a low dose of PEITC $(2 \mathrm{mg} / \mathrm{kg})$, had an inhibitory effect similar to that seen with pure PEITC. This indicates PEITC absorption probably in intestine. However, the extent of inhibition that resulted from Betong watercress was much lower than that caused by $2 \mathrm{mg} / \mathrm{kg}$ PEITC. This may be due to a variation of hydrolysis of the glucosinolates in the dry powders to PEITC in vivo. Such conversion occurs in the colon of rats and humans via microflora possessing myrosinase activity. In addition, glucosinolates may be converted to other classes of metabolites, of which ITCs constitute a small proportion. The released ITCs may be further metabolized to unknown compounds by colonic microflora before their absorption [22].

\section{CONCLUSION}

Inhibition of CF demethylation by PEITC and Betong watercress indicates an inhibition of
CYP1A2 and CYP2C. Since CYP1A2 plays a role in procarcinogen bioactivation, and interference with bioactivation mediated by cytochrome P450s is proposed as one mechanism of antitumor effect of xenobiotics, Betong watercress may be of benefit in chemoprevention, especially if one ingests a whole plant which contains more glucosinoate precursors.

\section{ACKNOWLEDGEMENT}

This work was funded by Prince of Songkla University, the Graduate School, and Natural Product Research Center. The authors thank Assoc.Prof.Dr. Kitichate Sridith and Mr. Charoensak Sae Wei, Princess Maha Chakri Sirindhorn Natural History Museum, for their kind assistance in authenticating the plant. The authors acknowledge Amphoe Betong Agricultural Office, Yala Province, Thailand for providing information about Betong watercress and plant samples. Thanks also to Dr Brian Hodgson for assistance with the English.

\section{REFERENCES}

1. Fenwick GR, Heaney RK, Mullin WJ. Glucosinolates and their breakdown products in food and food plants. Crit Rev Food Sci Nutr 1983; 18: 123-201.

2. Stoner GD, Morse MA. Isothiocyanates and plant polyphenols as inhibitors of lung and esophageal cancer. Cancer Lett 1997; 114: 113-119.

3. Gong $Y Q$, Fan $Y, W u D Z$, Yang $H, H u Z B$. In vivo and in vitro evaluation of erianin, a novel anti-angiogenic agent. Eur J Cancer, 2004; 40: 1554-1565.

4. Leclercq I, Desager JP, Horsmans Y. Inhibition of chlorzoxazone metabolism, a clinical probe for CYP2E1, by a single ingestion of watercress. Clin Pharmacol Ther 1998; 64: 144-149.

5. Lhoste EF, Gloux K, De Waziers I, Garrido S, Lory S, Philippe $C$, Rabot S, Knasmuller $S$. The activities of several detoxication enzymes are differentially induced by juices of garden cress, water cress and mustard in human HepG2 cells. Chem Biol Interact 2004; 150: 211-219.

6. Nakajima M, Yoshida R, Shimada N, Yamazaki H, Yokoi $T$. Inhibition and inactivation of human cytochrome P450 isoforms by phenethyl isothiocyanate. Drug Metab Dispos 2001; 29: 1110-1113.

7. Konuse $\mathrm{N}$, loannides $\mathrm{C}$. Chemoprevention effect of phenethyl isothiocyanate. Toxicology 2007; 240:184.

8. Kot M, Daniel WA. Caffeine as a marker substrate for testing cytochrome $P 450$ activity in human and rat. Pharmacol Rep 2008; 60: 789-797.

9. CIOMS. The International Guiding Principles for Biomedical Research Involving Animals, 2012 [cited 
2013 December 18]. Available from: http://www.cioms.ch/.

10. Grant DM, Tang BK, Kalow W. Variability in caffeine metabolism. Clin Pharmacol Ther 1983; 33: 591-602.

11. Caubet MS, Elbast W, Dubuc MC, Brazier JL. Analysis of urinary caffeine metabolites by HPLC-DAD: the use of metabolic ratios to assess CYP1A2 enzyme activity. J Pharm Biomed Anal 2002; 27: 261-270.

12. Jiao D, Yu MC, Hankin JH, Low S-H, Chung F-L. Total isothiocyanate contents in cooked vegetables frequently consumed in Singapore. J Agric Food Chem 1998; 46: 1055-1058.

13. USFDA. Guidance for Industry: Bioanalytical Method Validation, 2001 [cited 2012 November 9]. Available from: http://www.fda.gov/.

14. Ji Y, Kuo Y, Morris ME. Pharmacokinetics of dietary phenethyl isothiocyanate in rats. Pharm Res 2005; 22: 1658-1666.

15. Yasui-Furukori N, Takahata T, Nakagami T, Yoshiya G, Inoue $Y$, Kaneko S, Tateishi T. Different inhibitory effect of fluvoxamine on omeprazole metabolism between CYP2C19 genotypes. Br J Clin Pharmacol 2004; 57: 487-494

16. Claassen V. Review of the animal pharmacology and pharmacokinetics of fluvoxamine. $\mathrm{Br} J$ Clin Pharmacol 1983; 15(Supp/ 3): 349S-355S.
17. Hoglund AS, Lenman M, Falk A, Rask L. Distribution of myrosinase in rapeseed tissues. Plant Physiol 1991; 95: 213-221.

18. Chung FL, Morse MA, Eklind KI, Lewis J. Quantitation of human uptake of the anticarcinogen phenethyl isothiocyanate after a watercress meal. Cancer Epidemiol Biomarkers Prev 1992; 1: 383-388.

19. Johnson IT. Glucosinolates in the human diet. Bioavailability and implications for health. Phytochem Rev 2002; 1: 183-188.

20. Getahun SM, Chung FL. Conversion of glucosinolates to isothiocyanates in humans after ingestion of cooked watercress. Cancer Epidemiol Biomarkers Prev 1999; 8: 447-451.

21. Kassie F, Laky B, Gminski R, Mersch-Sundermann V, Scharf G, Lhoste E, Kansmuller S. Effects of garden and water cress juices and their constituents, benzyl and phenethyl isothiocyanates, towards benzo(a)pyrene-induced DNA damage: a model study with the single cell gel electrophoresis/Hep G2 assay. Chem Biol Interact 2003; 142: 285-296.

22. Rungapamestry V, Duncan AJ, Fuller Z, Ratcliffe $B$. Effect of cooking brassica vegetables on the subsequent hydrolysis and metabolic fate of glucosinolates. Proc Nutr Soc 2007; 66: 69-81. 